Gavrilidou P., Iliescu D.M., Baz R., Rusali L.M., Bordei P.

\title{
Anatomical peculiarities of the origin and traject of the superior thyroid artery
}

Discipline of anatomy, Department I - preclinical disciplines, Faculty of medicine, University "Ovidius" Constanţa

\begin{abstract}
The superior thyroid artery was evaluated on a number of 88 cases, using the methods of dissection and analysis of angioCT's. Each of the details was analyzed comparatively on both sides of the body assessing: the origin of the superior thyroid artery in relation to the carotid bifurcation, the face of the external carotid artery that gives origin and the traject of the artery from the origin to the glandular parenchyma. The origin of the superior thyroid artery was evaluated on a number of 64 cases, most frequently having its origin from the external carotid artery, an aspect met $53.125 \%$ of cases, at a distance that was between 1-18 mm. In $28.125 \%$ of cases the superior thyroid artery had its origin in the common carotid trunk at a distance of 1-10 mm caudal to the terminal bifurcation of the common carotid. In $18.75 \%$ of cases, the thyroid artery originated from the carotid bifurcation, which thus ends up by trifurcation. The side of the vessel that emerges the superior thyroid artery was assessed on 42 cases; most commonly the superior thyroid artery having its origin on the medial face, an aspect found in $66.67 \%$ of cases; in 23.81 $\%$ of cases originated from the posterior medial and only two cases (4.76\% of cases), both on the left side
\end{abstract}

\section{Iliescu D.M.}

Department of Anatomy, Faculty of medicine, University "Ovidius" Constanţa, Romania

Aleea Universitatii, Nr. 1, Campus B

Constanţa, Romania

dan@anatomie.ro
( $8.70 \%$ of cases on the left), the origin of the superior thyroid artery was located on the anterior, respectively faces of the common carotid artery. The traject of the superior thyroid artery was followed on 53 cases, in most cases the artery showing initially a horizontal traject (transverse) towards medially for $1-4 \mathrm{~cm}$, then became obliquely downward, an aspect met in 28.30 $\%$ of cases and in $22.64 \%$ of cases, the artery was obliquely downward from its origin. In $11.32 \%$ of cases the traject was obliquely ascending and in $9.43 \%$ of cases the artery was initially obliquely upward for 2-3 $\mathrm{cm}$, after which became transverse. For the remaining $28.30 \%$ of the cases we have met a number of other 5 different patterns of traject but in a small percentage for each of them (5.66\% of cases).

Key words: external carotid - collateral and terminal branches

\section{Introduction}

The superior thyroid artery always arises below the hyoid bone, sometimes $3-5 \mathrm{~mm}$ above the origin of the external carotid, but most commonly at the bifurcation of the common carotid, starting from the carotid bulb and always being the lowest collateral branch of the external carotid, which emerges from 
its anterior face [1.2], close to its origin [6]. It is relatively voluminous and its size is inversely with the one of the inferior thyroid of the same side $[1,3,4,5]$. At origin appears in the lower angle of the Farabeuf's triangle, then crosses medially the thyro-linguo-facial venous trunk, heading initially almost horizontal anterior- medially, slightly oblique supero-inferior, parallel and subjacent to the large horn of the hyoid and after a short traject of 6-10 mm curves inferiorly, describing a concave arch on the inferior constrictor of the pharynx $[1,3,4,5,6,7]$, which separates it from the thyroid cartilage; it may also pass towards the angle formed by the upper insertion of the sterno-thyroid muscle and the thyroid cartilage. Directed oblique anterior- inferior, it goes under the anterior belly of the omohyoid muscle then approach the lateral thyroid lobe, ending at variable level: sometimes it ends above the upper pole of the thyroid lobe in a fork of three terminal branches [1]; some other cases it continues anterior to the thyroid lobe as a main anterior branch, with other branches, thinner, detaching either as isolated vessels at different levels (sometimes 3-4 $\mathrm{cm}$ above and posterior the superior thyroid pole) or as a common trunk [1]. In its path, the superior thyroid artery is accompanied by the homonymous vein, the only satellite vein of a main thyroid artery and both are located in the superior vascular thyroid lamina. According to [8] the superior thyroid artery gives the following branches: an infrahyioid branch (R. infrahyoideus), the sternocleidomastoid artery (R. sternocleidamastoideus ), the superior laryngeal artery (A. laryngea superior) and the cricothyroid branch (R. cricothyroideus ). Are also cited the inferior laryngeal artery, the branch for the infrahyoid muscles, a thin branch for the superior cervical sympathetic ganglion (that emerges near its origin ) and several pharyngeal branches, distributed to the pharyngeal wall $[1,3,4,6]$. Also according to $[8]$, the terminal branches are three in number: anterior glandular branches ( $R$. glandularis anterior), posterior glandular branches ( $\mathrm{R}$. glandularis posterior) and lateral glandular branches (R. glandularis lateralis), cited also by [9]. When only two branches occur, they are one internal or anterior and the other or external [Braine and Funck-Brentano, cited by 1$]$.

\section{Materials and methods}

The superior thyroid artery was evaluated on a number of 88 cases, using the dissection and the analysis of angioCT's from a GE LightSpeed VCT64 Slice CT Scanner. Each of the markers was analyzed comparatively on both sides of the body, on a proper number of cases. Were studied: the origin of the superior thyroid artery in relation to the carotid bifurcation, the face of the external carotid artery that give birth to it and the arterial traject from its origin to the glandular parenchyma

\section{Results}

The origin of the superior thyroid artery was evaluated on a number of 64 cases, of which 34 cases were on the right side (53.125\% of cases) and 30 cases on the left ( $46.875 \%$ of cases). The most frequently the superior thyroid artery had its origin in the external carotid artery, an aspect that we met in 34 cases $(53.125 \%$ of cases), 20 cases were on the right side $(58.82 \%$ of right cases) and 14 cases on the left $(46.67 \%$ of cases). The origin of the superior thyroid artery from the carotid was done at a distance that varies widely in relation to the carotid bifurcation, ranging from 1 to $18 \mathrm{~mm}$. On the right side, where the distance was between 1-18 mm, we encountered 6 cases $(17.65 \%$ of right cases) when the distance was greater, ranging from 10 to $18 \mathrm{~mm}$. On the left side the distance was between 1-14 mm. In 18 cases $(28.125 \%$ of cases) the superior thyroid artery had its origin in the common carotid artery, 6 cases were on the right (17.65\% of right cases) and 12 cases on the left side ( $40 \%$ of left cases). The superior thyroid artery originated from the common carotid trunk at a distance of 1-10 mm caudal to the terminal division of the common carotid. The distance on the left side was lower, ranging from 1-4 mm while on the right side was comprised between 1 to $10 \mathrm{~mm}$. 
In 12 cases (18.75\% of cases), the superior thyroid artery originated from the carotid bifurcation, which thus ends up by trifurcation, with 8 cases on the right (23.53\% of right cases) and 4 cases on the left (13 $33 \%$ of left cases).

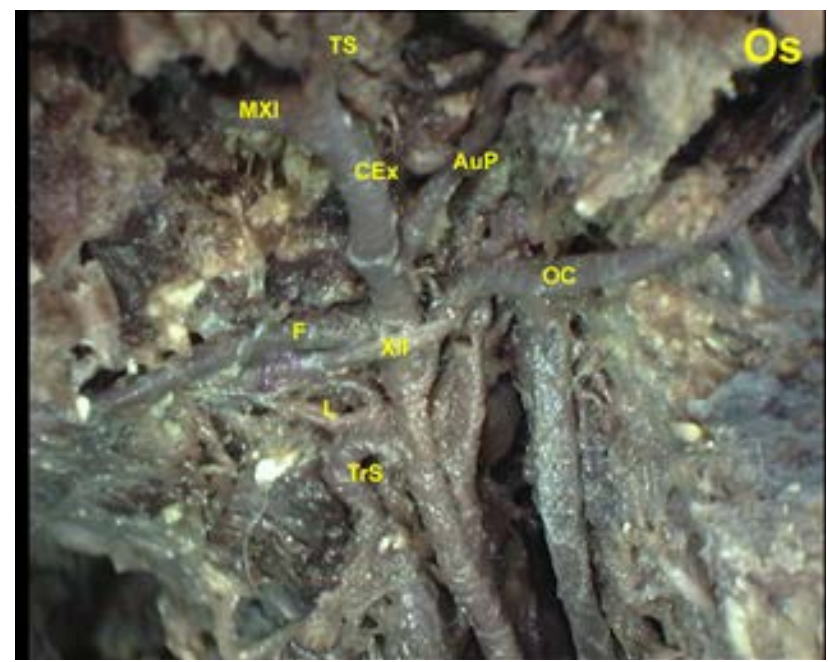

Figure 1 - Left superior thyroid artery originating from the medial face of the external carotid, with a traject in italic ,,$S^{\prime}$

The face of origin of the superior thyroid artery was assessed on a number of 42 cases, 19 cases were on the right (45.24\% of cases) and 23 cases on the left (54.76\% of cases). Most commonly, the superior thyroid artery had its origin on the medial face, an aspect found in 28 cases ( $66.67 \%$ of cases), with 7 cases on the right side (38.84\% of right cases) and 13 cases on the left (56.52\% of left cases). On the postero-medial face the arteries had their origins in 10 cases ( $23.81 \%$ of cases), 8 cases were on the right side $(42.10 \%$ of right cases) and 2 cases on the left ( $8.70 \%$ of left cases). In only two cases $(4.76 \%$ of cases), only on the left side (8.70\% of left cases), the origin of the superior thyroid artery was on the anterior face, i.e. posterior of the common carotid. Of the 14 cases originated in the common carotid artery, the superior thyroid originated from the medial face in 6 cases ( $42.86 \%$ of cases), all cases being on the left $(60 \%$ of cases on the left).

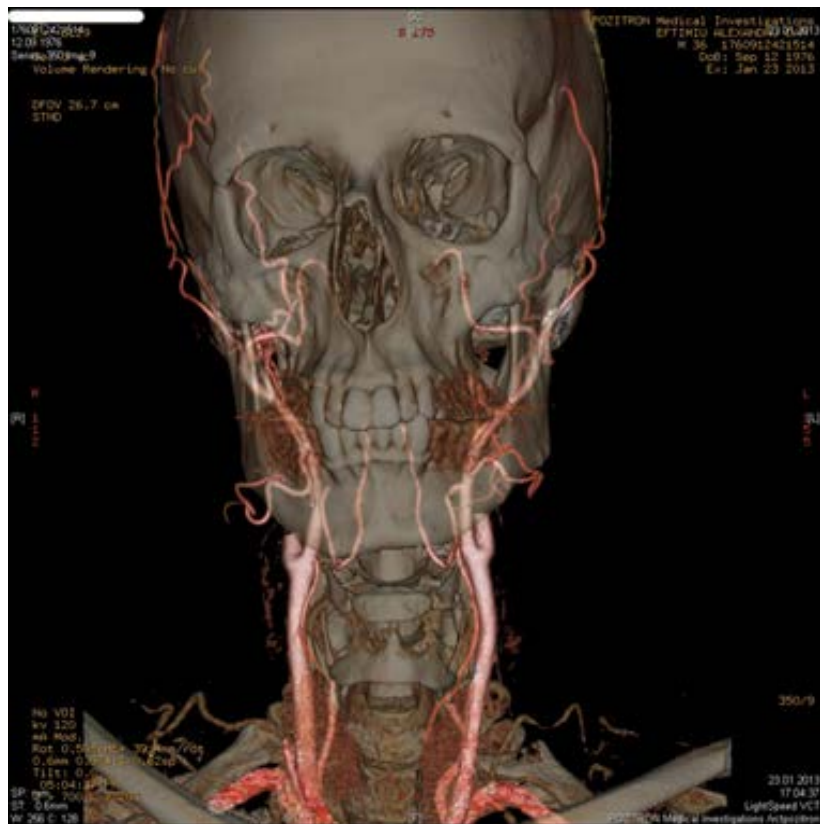

Figure 2 - Left superior thyroid artery originating from the medial face of the external carotid, with descending traject on the medial side of the carotid; right superior thyroid artery originating from the medial side of the carotid bifurcation and descending on the medial side of the carotid artery.

The thyroid arteries that had their origins from the external carotid ( 20 cases) had their origins only from the medial and postero-medial faces. On the medial aspect had their origins in 14 cases $(70 \%$ of cases), 7 cases were on the right (38.64\% of right cases) 7 cases on the left (30.43\% of left cases). On the postero - medial face had their origins in 6 cases (30\% of cases), 4 cases are on the right $(21.05 \%$ of right cases) and 2 cases on the left $(8.70 \%$ of cases left). In 8 cases $(19.05 \%$ of the cases) the thyroid artery had the origin from the terminal division of the common carotid, in all cases where it was originally placed on the medial face, 4 cases on each of the two body parts ( $50 \%$ of cases right, or left). 


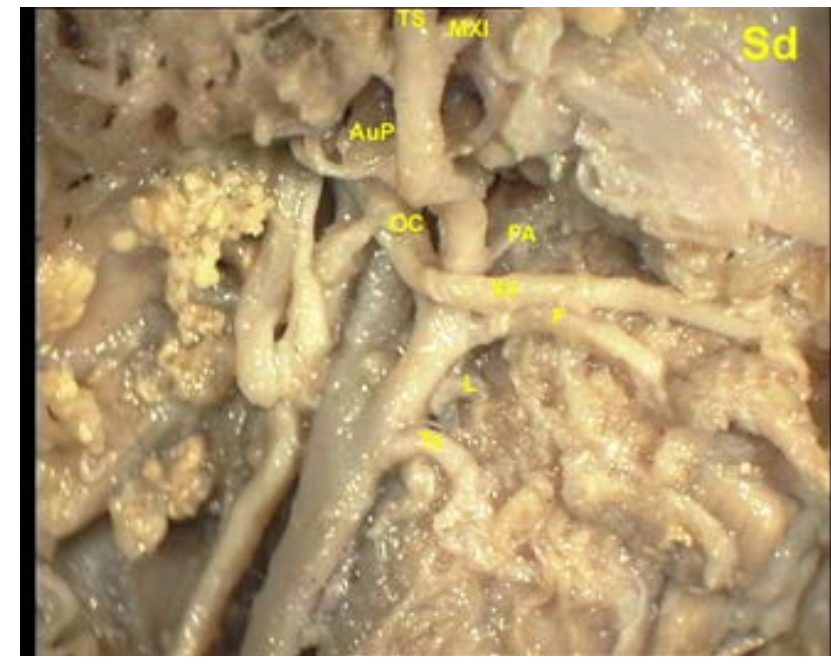

Figure 3 - Right common carotid artery trifurcated: the internal carotid (the largest), the external carotid and the superior thyroid artery (the thinnest), with a curve with inferior concavity.

Regarding the traject of the superior thyroid artery, it was followed on 53 cases, of which 23 cases were on the right $(43.40 \%$ of the cases) and 30 cases on the left (56.60\% of cases). In most cases, the artery was initially horizontal (transverse) towards medial, for variable $1-4 \mathrm{~cm}$, then became obliquely downward, an aspect found in 15 cases ( $28.30 \%$ of cases), 6 cases the right ( $26.09 \%$ of right cases) and 9 cases on the left ( $30 \%$ of left cases). In 12 cases ( $22.64 \%$ of cases), the artery was at origin only obliquely downward, 6 cases were on the right (26.09\% of right cases) and 6 cases on the left ( $20 \%$ of left cases). In 6 cases ( 11.32 $\%$ of cases) was obliquely upward, two cases were on the right ( $8.70 \%$ of right cases) and 4 cases on the left $(13.33 \%$ of cases left). In 5 cases $(9.43 \%$ of cases) it had initially an obliquely upward trajectory for 2-3 cm, after which became transverse, with 3 cases on the right (13.04\% of cases right) and 2 cases on the left (6.67\% of left cases). In the remaining 15 cases $(28.30 \%$ of cases) we have met the following patterns, with three cases for each variant: 1 . initial transverse for the first $1-2.5 \mathrm{~cm}$, after which became vertical, all cases on the left (10\% of left cases); 2 . initial upward trajectory over a distance of 0.5-2 $\mathrm{cm}$, describing a curve concave inferiorly and then oblique downward, an aspect also met only on the left side (10\% of left cases); 3 . inverted italic "S", 1 case on the right (4.35\% of right cases) and 2 cases on the left $(6.67 \%$ of left cases $) ; 4$. initial oblique downward for a distance of 1-3 cm, after which it became transversally, all on the right side ( $13.04 \%$ of the right cases); 5. obliquely downward in front of the external carotid or down on its sidewall, with 2 cases on the right $(8.70 \%$ of right cases) and 1 case on the left $(3.33 \%$ of left cases).

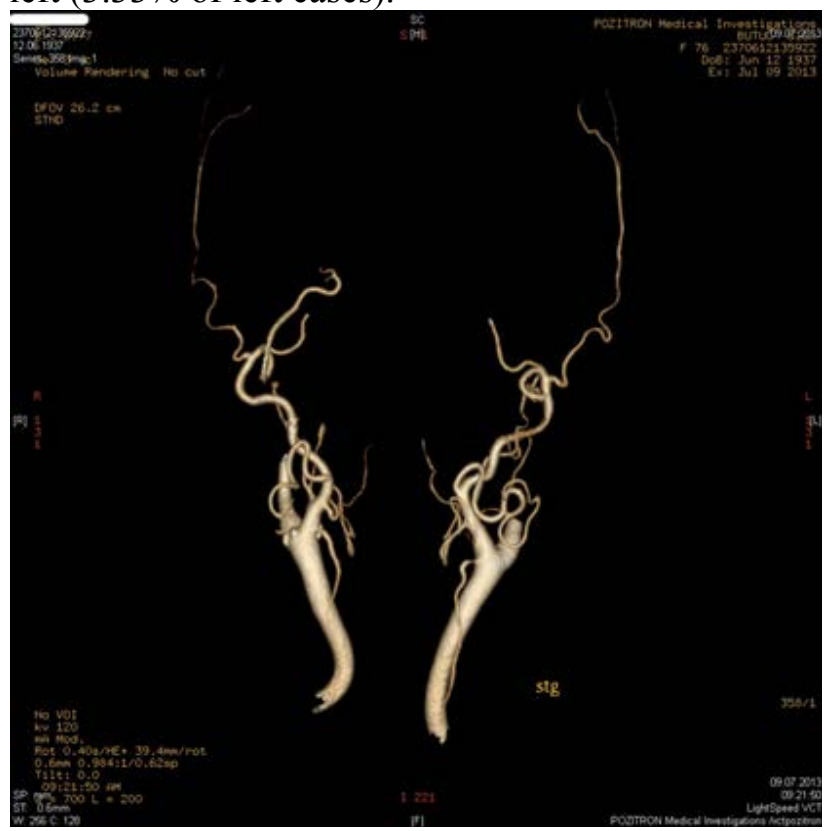

Figure 4 - Left superior thyroid artery originating from the medial face of the common carotid and right superior thyroid artery originating from the medial face of the external carotid.

\section{Discussions}

Making a brief evaluation of the literature, it is found that [1] shows that the superior thyroid artery always arises below the hyoid bone, sometimes 3-5 $\mathrm{mm}$ above the origin of the external carotid, but most often in the common carotid bifurcation, leaving from the carotid bulb, always being the most inferior collateral of the external carotid, which emerges from the front of it. Regarding the traject of the superior 
thyroid artery, [1] states that when the artery has a low origin, it always shows a short ascending portion that remains attached to the origin of the external carotid and the upper part of the carotid bulb, previously to its characteristic curve. [3] and [4] states that the superior thyroid arises above the bifurcation of the common carotid, sometimes at the bifurcation or may arise even in the common carotid. By [9], the superior thyroid emerges near the bifurcation passes infero-medially, under it being a gap of 10-12 mm were is practiced the ligation of the common carotid. According to [10], the superior thyroid artery arises from the front of the external carotid, right next to its origin. [11] founds that the ascending pharyngeal may be the first or second branch of the external carotid artery while [12] describes a case in which from the right external carotid artery, near its origin, emerged the superior thyroid, the lingual and the occipital arteries, while the facial originated from the distal part of the carotid.

It is noted that although not go into details in so-called classical specialized treaties, there is some contradiction in particular with regard to the origin of the superior thyroid artery; therefore, our results, as compared to those described by [1], showed that the most common pattern of origin is with the superior thyroid artery arising from the external carotid, followed by the common carotid and in only $18.75 \%$ of the cases emerges from the level of the carotid bifurcation, a possibility that [1] gives it as the most frequent. $[3,4,9]$ states that the origin of the superior thyroid artery is above the origin of the external carotid, [3] and [4] indicating the possibility of origin from the common carotid bifurcation or the common carotid, while we found as most common the origin from the common carotid, followed by the bifurcation origin with a difference of about 10 percent. [1] and [10] claim that the most common origin is the anterior face of the carotid while we found the highest percentage from the medial face and from the anterior in only about $16 \%$ of cases. Regarding the ascending pharyngeal as the first branch of the external carotid, a variant mentioned by [11], we have not encountered any similar case.

Only [13] describes the percentage possibilities of origin of the superior thyroid artery, most often finding that the origin is located from the external carotid ( $50 \%$ of cases).

Table I

\begin{tabular}{|l|c|c|c|}
\hline Author & $\begin{array}{c}\text { Ext. } \\
\text { Carotid } \\
\text { Orig. }\end{array}$ & $\begin{array}{c}\text { Comm. } \\
\text { Carotid } \\
\text { Orig. }\end{array}$ & $\begin{array}{c}\text { Carotid } \\
\text { bifurcation }\end{array}$ \\
\hline Lippert & $50 \%$ & $20 \%$ & $20 \%$ \\
\hline $\begin{array}{l}\text { Personal } \\
\text { cases }\end{array}$ & $53.125 \%$ & $28.125 \%$ & $18.75 \%$ \\
\hline
\end{tabular}

The values are larger with $8.125 \%$ only when the origin is from common carotid artery; in other cases the differences are about $3.125 \%$ higher for the origin from the external carotid and $1.25 \%$ lower in the case of the origin from the carotid terminal division (Table I).

Regarding the frequency of origin of the superior thyroid artery from the common carotid, the literature is rich in references (Table II).

Table II

\begin{tabular}{|l|c|}
\hline \multicolumn{1}{|c|}{ Author } & Percentage \\
\hline Quain & 14.1 \\
\hline Adachi & 13.3 \\
\hline Faller & 18 \\
\hline Poisel & 6.41 \\
\hline Akyol & 1 \\
\hline Lippert & 20 \\
\hline Personal cases & 28.125 \\
\hline
\end{tabular}

Our results are greater than all the other authors cited, the difference being of $27 \%$ to [14], of more than $21 \%$ than [15], of about $15 \%$ to [16], $14 \%$ from Quain [cited by 17], more than $10 \%$ than [18] and as I mentioned a $8.125 \%$ difference from [13].

\section{Conclusions}

The origin of the superior thyroid artery is, in $46.875 \%$ of cases, outside the external carotid; for the left superior thyroid this percentage is higher 
(53.33\% of cases). When the superior thyroid artery originates from the carotid bulb, its size is larger, so that seems that the common carotid trifurcates. This arrangement is an inconvenience to external carotid ligation at origin as when passing a wire over the origin of the superior thyroid artery, there is sometimes a risk of common carotid ligation prior to its terminal branch [Sebileau, quoted by 1]. The superior thyroid artery traject depends on the level of its origin, the ascending and transverse trajectory cases occurring more frequently when the origin was from the common carotid artery or from its terminal division. This criteria also applies for the face of origin of the superior thyroid artery, so where the origin was from the termination of the carotid artery, the face of origin was mostly the medial one or the postero-medial $(71.43 \%$ of cases). The differences encountered between our results and those in the literature, we believe that may be attributed to the number of examined cases.

\section{References}

1. Paturet G. (1964). Traité d'Anatomie Humaine. (pp. 258-323). Paris: Ed. Masson

2. Fontaine C. \& Drizenko A. (1996). Les artères de la tête et $d u$ cou. In: Chevrel J.P. Anatomie clinique. Tête et cou. (pp. 401-407). Paris: Ed. Springer-Verlag

3. Testut L. (1921). Traité d'anatomie humaine. Angéiologie, livre IV. (pp. 127-144). Paris: Ed. Gaston Doin.

4. Testut L. (1924). Traité d'anatomie humaine. Angéiologie. (pp. 604-606, 621, 710-711, 714715). Paris: Ed.Gaston Doin

5. Gray's Anatomy. (2005). Thirty-ninth edition. (pp. 543-547).Ed.Elsevier-Churchill Livingstone

6. Rouvière H. \& Delmas A. (1997). Anatomie humaine. descriptive, topographique et fonctionn elle. Tome 2. Tronc. (pp. 196-229). Paris: Ed. Masson

7. Kamina P. (1997). Anatomie Clinique. 10. Tome
1. Tête et cou. (pp. 64-74). Paris: Ed. Maloine

8. ****** Federative Committee on Anatomical Terminology. (1988). Terminologia Anatomica. International Anatomical Terminology. (pp. 7981). Stuttgart: Thieme Verlag

9. Bouchet A. \& Cuilleret J. (1991). Anatomie topographique, descriptive et fonctionnelle. Vol.2. Le cou. Le thorax. (pp. 753-757). Paris: Ed. Simep

10. Anatomie de l'artère carotide externe Retrieved from: htpp://www.imedecin.com

11. Moore L.K. \& Dalley F.A. (2001). Anatomie médicale. Aspects fondamentaux et applications cliniques. (pp. 1012-1019). Bruxelles: Ed. De Boeck Université

12. Gluncic V., Petanjek Z., Marusic A. \& Gluncic I. (2001). High bifurcation of common carotid artery, anomalous origin of ascending pharyngeal artery and anomalous branching pattern of external carotid artery. Surg.Radiol.Anat., 23, 123-125

13. Lippert H. \& Pabst R. (1985). Arterial Variations in Man. Classification and Frecvency. (pp. 8387). Munchen: Ed. J.F.Bergmann Verlag

14. Akyol M.U., Koç C., Ozcan M. \& Ozdem C. (1997). Superior thyroid artery arising from the common carotid artery. Otolaryngol. Head Neck Surg., 116, 701-705

15. Poisel S. \& Golth D. (1974). Zur Variabilitat der groben Arterien im Trigonum caroticum. Wien Med.Wochenschr., 124, 229-232

16. Adachi B. (1928). Das Arteriensystem der Japaner. (pp. 43-96). Kyoto: Verlag der Kaiserlich Japanischen Universitat

17. Issing P.R., Kempf H.G. \& Lenarz T. (1994). Mitteilung einer klinisch relevanten Variation der Arteria thyroidea superior.Laryngorhinootologie. $73,536-537$

18. Faller A. \& Scharer O. (1947). Uber die Variabilitat der Arteriae thyroideae. Acta Anat. 4, $119-122$ 